\title{
Acumulação por espoliação e redes de transporte público: o Corredor Metropolitano Noroeste em Campinas-SP
}

\begin{abstract}
Resumo
Este artigo objetiva relacionar aspectos do processo de acumulação por espoliação com dinâmicas de desenvolvimento de redes de transporte público, a partir do recorte empírico do Corredor Metropolitano Noroeste, na Região Metropolitana de Campinas (SP). Grandes projetos de infraestrutura como esse corredor implicam uma diversa trama de intencionalidades políticas, dentre as quais há as que têm como finalidade a acumulação de caráter rentista. Discursos do planejamento tecnocrático se colocam como neutros e comprometidos com o bem comum e, por isso, são usados para legitimar propostas de intervenção nas redes de transporte coletivo. A viabilidade dessas transformações na organização do espaço está condicionada, no entanto, a diferentes objetivos especulativos. Em torno do Estado, a promoção imobiliária e a privatização do patrimônio público são determinantes para que propostas de renovação das materialidades avancem ou desvaneçam.
\end{abstract}

Palavras-chave: redes, transporte público, espoliação, promoção imobiliária, privatização.

\begin{abstract}
ACCUMULATION BY DISPOSSESSION AND PUBLIC TRANSPORT NETWORKS: THE CORREDOR METROPOLITANO NOROESTE IN CAMPINAS-SP

This article relates the process of accumulation by dispossession with the development of public transport networks, with Corredor Metropolitano Noroeste in Campinas metropolitan area (SP) as case study. In the plot of political intentions
\end{abstract}


that orbit projects like that, there are those that are rent-seeking. Discourses of technocratic planning are supposed to be neutral and committed to the common good and, therefore, legitimate proposals for intervention in collective transport networks. Nevertheless, the viability of these transformations in the organization of the space is actually committed to speculative objectives. Surrounding the State, real estate and privatization of public properties hold the capacity for those proposals to advance or to fade away.

Key-words: networks, public transport, dispossession, real estate, privatization.

\section{Introdução}

Acumulação por despossessão é como Harvey (2004) se refere às diversas práticas de acumulação e reprodução ampliada do capital, fundamentado na relação entre capital e trabalho. Marx (1996[1867]) considerava essa dinâmica repleta de depredação, fraudes e violência como restrita às etapas primitivas do capitalismo; Harvey (2004) argumenta, no entanto, que são estratégias permanentes do próprio sistema econômico. Às antigas formas de expropriação dos meios de produção que deram origem ao capitalismo se somam, hoje, novos mecanismos mais sofisticados de despossessão.

Dentre outros meios, a acumulação por espoliação se vale do que Harvey (2011) chama de destruição criativa da terra, que se dá quando as transformações do espaço geográfico tomam impulso pelas "necessidades especulativas de acumulação adicional e, só secundariamente, tomando em conta as necessidades das pessoas" (HARVEY, 2011, p. 152). A pesquisa da qual resultou este artigo mobiliza essa ideia por perceber a importância do rentismo no desenvolvimento de projetos de ampliação das redes de transporte público nas cidades brasileiras. A despeito dos argumentos técnicos e científicos que são empregados para justificar novos empreendimentos, o avanço das infraestruturas é protagonizado pelos interesses de elites patrimonialistas locais, como descritas por Brandão (2010), em permanente busca por ganhos adicionais com a conivência e a colaboração do Estado.

O estudo de caso de um projeto de corredor metropolitano é apresentado como recorte empírico. A metodologia de análise esteve centrada na metamorfose histórica desse empreendimento, desde sua concepção inicial 
até os estágios mais recentes de implantação. Por meio de documentos técnicos oficiais, de apresentações de audiências públicas e de visitas técnicas junto às instituições responsáveis foi possível associar as transformações nos planos do corredor de ônibus a um rizoma de actantes ${ }^{1}$. Dentro dessa trama, este texto destaca a importância da especulação imobiliária e das iniciativas de privatização do patrimônio público como mecanismos espoliativos mais notáveis.

\section{0 projeto do Corredor Metropolitano Noroeste}

O Corredor Metropolitano Noroeste ${ }^{2}$ é um projeto da Empresa Metropolitana de Transporte Urbanos (EMTU), empresa pública vinculada à Secretaria de Transportes Metropolitanos (STM) do governo do estado de São Paulo. Foi proposto pouco tempo após a institucionalização da Região Metropolitana de Campinas (RMC) pela Lei Estadual No 870, do ano 2000, com vistas a "proporcionar a reorganização do transporte público de passageiros na região" a partir de integrações físicas e tarifárias, construção de faixas exclusivas para ônibus com tecnologia de porta à esquerda e "replanejamento urbano com qualidade e preocupação ambiental" (EMTU, 2005).

A implantação dessa infraestrutura de transporte vem ocorrendo desde meados dos anos 2000 como uma das ações mais incisivas do governo estadual na organização territorial da RMC. Seu objetivo explícito é sistematizar um novo arranjo do transporte coletivo intermunicipal em uma área de forte integração metropolitana, constituída por Campinas, Hortolândia, Sumaré, Monte Mor, Nova Odessa, Americana e Santa Bárbara d'Oeste. Para isso, tem a pretensão de deslocar os fluxos de ônibus de passageiros das rodovias da região, especialmente a Via Anhanguera (SP-330), e concentrá-los em um eixo viário totalmente novo.

Entre os anos de 2006 e 2008 as obras se desenvolveram em três lotes e priorizaram o trecho com maior demanda de ônibus metropolitanos, entre Sumaré, Hortolândia e Campinas (SÃO PAULO, 2003). Por meio do Lote $1 \mathrm{~A}$ se deu a adequação viária e a implantação de faixas exclusivas para ônibus, duas paradas e uma estação de transferência na Avenida 
Lix da Cunha, via com maior carregamento de tráfego de coletivos da RMC (FECAMP, 2006). Nesse mesmo conjunto de obras incluiu-se a construção do novo Terminal Metropolitano Magalhães Teixeira, no centro de Campinas, onde estão integradas fisicamente a maioria das linhas intermunicipais da região. Com o Lote 1B, desenrolou-se a duplicação e a instalação de faixas prioritárias para ônibus na Avenida Olívio Franceschini, em Hortolândia. O Lote 2, por fim, adequou a pavimentação e a geometria de vias vicinais nas ligações perimetrais de Hortolândia com Sumaré e com o bairro campineiro do Campo Grande, além da construção do novo Terminal Metropolitano de Hortolândia.

Apesar da inauguração em 2008, a operação do transporte público metropolitano no corredor ficou comprometida pela desarticulação entre os trechos e pela ausência de terminais e estações que estavam previstos no esboço inicial, essenciais à plena operação de um sistema de ônibus tronco-alimentador. Cinco anos depois, o projeto foi retomado pelo governo estadual, mas não havia sido concluído até o primeiro semestre de 2020. Sob a denominação de Lote 3, a EMTU vem empreendendo a ligação do subcentro metropolitano de Americana com as cidades de Santa Bárbara d'Oeste e Nova Odessa. Também foram incluídas nesse lote as obras remanescentes do trecho já inaugurado, o que inclui ligações entre vias e alguns terminais e estações de transferência em Hortolândia e Sumaré.

A figura 1 ilustra o estado do projeto até a conclusão deste artigo. As linhas amarelas contínuas são os trechos já inaugurados, enquanto as linhas amarelas pontilhadas representam suas ligações remanescentes, em obras ou previstas. A linha laranja descontínua corresponde às obras avançadas de expansão no subcentro metropolitano de Americana. E a linha cinza, por fim, equivale às vias operacionalmente necessárias ao corredor, mas fora da jurisdição da EMTU - a Rodovia Jornalista Francisco A. Proença (SP-101), administrada pela concessionária Rodovias do Tietê, e a Avenida da Emancipação, em atual processo de reestruturação viária pela Prefeitura de Hortolândia.

Os investimentos na infraestrutura já instalada somam $\mathrm{R} \$ 139,4$ milhões ${ }^{3}$, provenientes do Tesouro do estado de São Paulo. Nas obras civis em curso foram investidos mais $R \$ 224,8$ milhões $^{4}$, valor que não inclui a nova ligação entre Sumaré e Hortolândia nem outras ações complementares 
significativamente custosas, como os projetos técnicos, as desapropriações de imóveis e as licenças ambientais. Para justificar esse empreendimento milionário, os seus proponentes tiveram que enfatizar a sua importância para a organização territorial da RMC. Pode-se afirmar, com os termos de Foucault (2005), que desenvolveram discursos de verdade como mecanismos de poder, no intuito de que suas ações se tornassem legítimas perante a opinião pública. Assim, o Corredor Metropolitano Noroeste, enquanto rede geográfica, aparece como imagem do poder de certo conjunto de agentes e define escalas de ação social (RAFFESTIN, 1993; DIAS, 2005). A despeito da neutralidade que as planilhas e os gráficos dos planos tecnocratas parecem transmitir, é preciso analisá-los como instrumentos de exercício do poder no território.

$\mathrm{Na}$ busca por mobilizar agentes a favor do projeto, o poder público estadual enfatizou a saturação das vias regionais até então usadas pelo tráfego intrametropolitano, principalmente a Via Anhanguera. Com o novo corredor, alega a EMTU (2005), o transporte coletivo intermunicipal não mais concorreria por espaço nas rodovias com o fluxo de automóveis, caminhões e ônibus rodoviários. Além de diminuir os riscos inerentes à circulação mista entre passageiros e cargas, essa alteração colaboraria também com a qualidade dos transportes, na medida que ampliaria a capacidade de investimento do sistema metropolitano de ônibus. Primeiramente, reduzir-se-iam os congestionamentos e o tempo de deslocamento, o que aproximaria o sistema de transporte público de sua função social principal, que é a de promover a mobilidade dos trabalhadores. Mais do que isso, um sistema tronco-alimentador de ônibus tenderia a otimizar a relação entre número de passageiros (receita tarifária) e as distâncias percorridas pelos coletivos (custos operacionais), no sentido de um equilíbrio econômico-financeiro para as empresas de ônibus. 


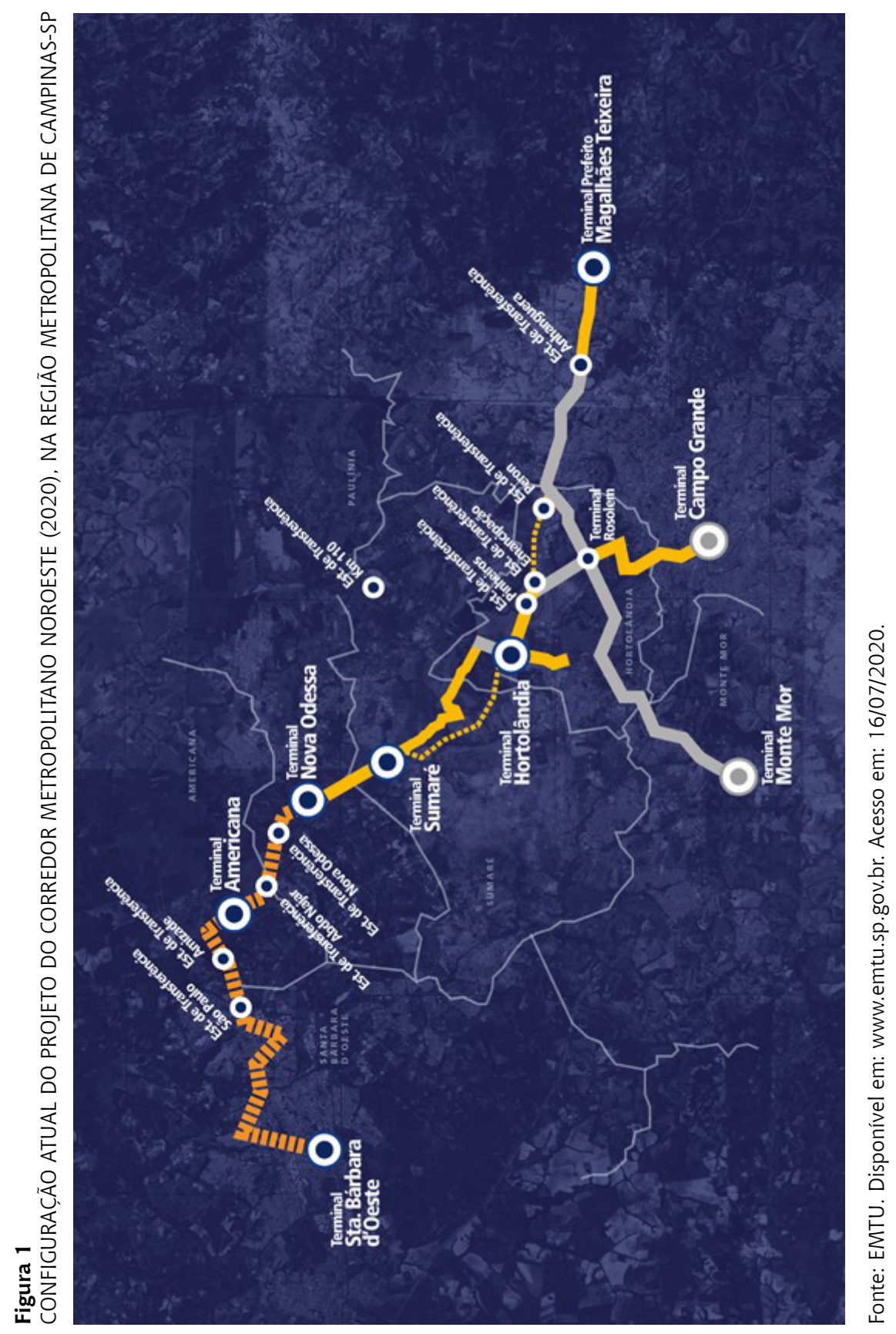

42. GeoTextos, vol. 16, n. 2, dezembro 2020. V. da Silva. 37-58 


\section{Cooperação e conflito}

Quando o projeto do Corredor Metropolitano Noroeste ganhou força para se concretizar, em meados da década de 2000, sobre ele incidiram também as especulações de agentes externos ao poder público estadual. Em torno da proposta se consolidaram grupos de interesse, ora convergentes entre si, ora divergentes. Apesar da aparente objetividade nos discursos da EMTU, muitas outras intencionalidades também passaram a participar do desenvolvimento desse empreendimento, cada qual em busca de seu quinhão. E a essa conjugação de agentes diversos, singular no tempo e no espaço, combina-se o papel ativo do território, isto é, da herança de objetos geográficos que condicionam as ações presentes tanto quanto são por ela condicionados (SANTOS, 1996). O plano que outrora parecia imparcial e cientificamente determinado, ao sair da latência à existência transparece como elemento geográfico politicamente circunstanciado. Em torno dela se consolidou um ator-rede (LATOUR, 2008), ou melhor, um rizoma de actantes (LATOUR, 2013).

Muitas materialidades do espaço metropolitano campineiro herdadas do passado como rugosidades podem ser mencionadas pelo seu papel ativo na consolidação do projeto. A estruturação do sistema de transportes pelo modal rodoviário (FERNANDES; BRANDÃO; CANO, 2002) certamente marcou a escolha pela tecnologia de corredores de ônibus, excluindo-se as outras possibilidades técnicas, como os trilhos. Também as faixas non aedificandi do sistema elétrico regional guiaram a elaboração das diretrizes gerais do corredor, pois mais de 30 dos 47 quilômetros totais previstos ocupam essas faixas de terra públicas disponíveis (FUPAM, 2016). Do mesmo modo, a ampla área subutilizada dos arredores da antiga estação ferroviária central de Campinas possibilitou a implantação, aí, do principal terminal metropolitano da região.

Quanto aos agentes que intervêm no projeto, direta e indiretamente, é conveniente separá-los segundo a tipologia proposta por Antas Jr. (2004): Estado, corporações e organizações de solidariedade. Para o autor, esse esforço analítico possibilita compreender a regulação híbrida do território e reconhecer a coexistência de normas públicas e corporativas nos seus usos. Contrapõe-se, assim, à ideia bastante recorrente no senso comum e 
no discurso midiático de que o Estado é protagonista único nas transformações do espaço público. As empresas são, nesse viés, muito mais do que figurantes ou coadjuvantes.

O poder estatal, no Brasil, é representado pelos três níveis de entes federados: a União, os estados e os municípios. A União praticamente não figura na trama do projeto do Corredor Metropolitano Noroeste, embora sua participação seja significativa no financiamento de muitas outras obras de mobilidade urbana em todo o país (SALOMÃO, 2017). O estudo de caso escolhido dá destaque ao governo do estado de São Paulo e a sete governos municipais diretamente relacionados, que estabelecem articulações institucionais entre si em função do atual ordenamento jurídico e político-administrativo do território brasileiro (CASTILLO; TOLEDO JR.; ANDRADE, 1997).

O poder corporativo apresenta-se, no mencionado contexto de regulação híbrida e em relação ao projeto do corredor, em, pelo menos, três dimensões. Uma primeira, que está relacionada à produção propriamente dita, inclui as firmas de consultoria que elaboraram os planos básicos e executivos e as empreiteiras responsáveis pelas obras civis, inclusive suas fornecedoras. Uma segunda dimensão, de caráter especulativo, se manifesta principalmente através dos agentes imobiliários com propriedades nas áreas de influência do corredor. E uma terceira é formada pelas empresas que prestam o serviço de ônibus na RMC, cujas redes operacionais podem variar significativamente com o advento de novas infraestruturas. Em sua busca inexorável por lucro, é frequente que esses diversos agentes se contradigam e entrem em conflito entre si ou com o Estado. Também é comum o conflito de interesses com os poderes colaborativos das muitas organizações de solidariedade, desde os grupos da sociedade civil organizada que reivindicam melhorias no transporte público até as associações patronais e suas demandas.

Os argumentos apresentados nas próximas seções deste artigo têm o objetivo de elucidar as relações entre o poder público e o poder corporativo. Nesse sentido, o Corredor Metropolitano Noroeste parece servir à acumulação por espoliação porque não é somente a exploração da mão de obra que garante o lucro das empresas envolvidas. A promoção imobiliária espolia o orçamento público porque converte parte dos gastos do projeto 
em valor de troca dos imóveis sob a área de influência do projeto. Também o faz a iniciativa de privatização das infraestruturas, pois as vencedoras de licitações têm garantias de lucratividade com as obras concluídas, enquanto o Estado encampa o ônus da dívida pública.

\section{O papel da promoção imobiliária}

Para Rodrigues (1996), a especulação imobiliária é um processo de apropriação privada da riqueza produzida coletivamente. Se dá pela valorização das propriedades imóveis lindeiras a equipamentos de uso coletivo cujos custos de implantação e renovação são socializados através do Estado. Do erário público provêm os investimentos para a construção de equipamentos coletivos. Ocorrem melhorias nos níveis de acessibilidade aos serviços urbanos nas áreas adjacentes e o valor de uso destas é ampliado; concomitantemente, elevam-se os preços dos imóveis (VILLAÇA, 2001; KOWARICK, 1979), isto é, seu valor de troca. Bastante comum no atual período da formação socioespacial brasileira, a especulação imobiliária é um mecanismo de acumulação por espoliação porque a totalidade dos cidadãos contribui compulsoriamente com projetos públicos, via tributação, mas apenas um conjunto restrito de pessoas detém a renda da terra excedente gerada.

O desenvolvimento da especulação imobiliária conta com um sistema de agentes econômicos genericamente denominados promotores imobiliários (FIX, 2007). Estes se portam de maneira ativa ao longo do processo de implantação de infraestruturas urbanas, na medida em que orbitam as instituições públicas e direcionam os investimentos do Estado em equipamentos de uso coletivo para algumas áreas a fim de elevar o valor de troca das suas propriedades imóveis. Em um contexto de recursos públicos limitados, isso implica reduzir investimentos estatais noutras áreas que carecem deles, mas onde o rentismo sobre a terra é menos lucrativo. Assim, consolida-se um grupo de pessoas marginalizadas para as quais seus impostos não retornam nem na forma de serviços públicos de qualidade, nem na forma de valorização imobiliária, pois foram desviados 
para equipamentos coletivos em porções da cidade onde os ganhos com especulação podem ser maximizados.

Alterações significativas na proposta original do Corredor Metropolitano Noroeste, se comparadas ao projeto executivo atual, dão indícios de ações dos promotores imobiliários. Trata-se de um ponto muito difícil de ser demonstrado, uma vez que esses agentes atuam como verdadeiros blocos de poder periféricos à administração pública (GALLO, 2014; CATAIA, 2013), em interstícios herméticos da política. Diante dessa dificuldade metodológica, o argumento principal em defesa da hipótese é que muitas alterações não apresentam justificativas técnicas ou orçamentárias plausíveis. Somente a promoção imobiliária explica alguns dos porquês dessas mudanças.

As administrações públicas municipais têm um papel central no atendimento às reivindicações especulativas imobiliárias, o que é válido para o Corredor Metropolitano Noroeste assim como para boa parte das outras intervenções públicas no território. Ao redor desse nível de governo, as elites rentistas de alcance local formam poderes periféricos e sistematizam demandas mais ou menos pragmáticas para si. Em seguida, os municípios encaminham essas demandas ao governo estadual, como se representassem o interesse local geral, de todos os cidadãos daquela localidade.

Para pressionar as ações do governo paulista de acordo com os interesses de suas elites, as autoridades municipais se valem da autonomia expressa pelo Artigo 35 da Constituição Federal (BRASIL, 1988). Essa norma permite inferir que os estados precisam da autorização dos municípios para intervir em seus respectivos territórios. Em troca da autorização para o estado prosseguir com as obras do Corredor Metropolitano Noroeste, os poderes municipais podem barganhar mudanças no traçado, novas localizações de terminais e estações e priorização e supressão de trechos com vistas às proposições de suas elites. Tal submissão da EMTU aos caprichos municipais foi reconhecida pela própria empresa, nas visitas técnicas realizadas ao longo das pesquisas que subsidiaram este artigo $^{5}$.

Em muitos pontos do atual projeto executivo podem ser identificadas as alterações impostas pelos municípios à empresa estadual. As mudanças de trajeto da Avenida Campos Sales para a Avenida Europa 
(Americana), da Avenida Emancipação para a Avenida Antônio da Costa Santos (Hortolândia) e o embate da Associação Comercial e Industrial de Sumaré contra o uso da Avenida Rebouças (Sumaré) como corredor são muito importantes para compreender a análise aqui proposta, sendo discutidos detalhadamente em Salomão (2014; 2017). Dadas as limitações formais deste texto, contudo, tome-se como exemplo a questão da localização dos terminais de ônibus.

$\mathrm{Na}$ proposta original do Corredor Metropolitano Noroeste (figura 2), os terminais metropolitanos e as estações de transferência estão dispostos ao longo do corredor de modo a garantir a integração física das linhas de ônibus da região em um sistema tronco-alimentador. Para tanto, a maior parte desses equipamentos tem de se localizar em áreas que permitam a articulação dos centros com alta demanda por viagens e os loteamentos residenciais espraiados. Assim, é possível reduzir o número de linhas metropolitanas radiais do tipo bairro-centro metropolitano, substituindo-as por linhas alimentadoras municipais de média capacidade e linhas troncais interurbanas de alta capacidade - estas, operando com prioridade de tráfego ao longo do corredor.

Contudo, os atuais terminais de Hortolândia e Santa Bárbara d'Oeste não seguem essa diretriz, como já observado na figura 1. A partir do projeto executivo, ambos foram deslocados de uma posição geográfica funcional e acabaram ficando de fora de pontos de articulação entre os bairros e os centros de atração de viagens. De acordo com a pesquisa sobre origem e destino na RMC (STM, 2012), a maior parte das viagens de ônibus de Hortolândia tem como destino Campinas (42\%), mas o terminal foi construído no sentido de Sumaré, para onde se direcionam apenas 7\% dessas viagens. O mesmo vale para Santa Bárbara d'Oeste, pois o terminal foi construído na saída para Piracicaba, às margens da vicinal SP-306, e está fora da rota tanto dos deslocamentos municipais (69\% do total de viagens de ônibus) quanto dos deslocamentos intermunicipais para Americana (24\% desse mesmo total). 


\section{Figura 2}

PROPOSTA ORIGINAL DO CORREDOR METROPOLITANO NOROESTE (2005)

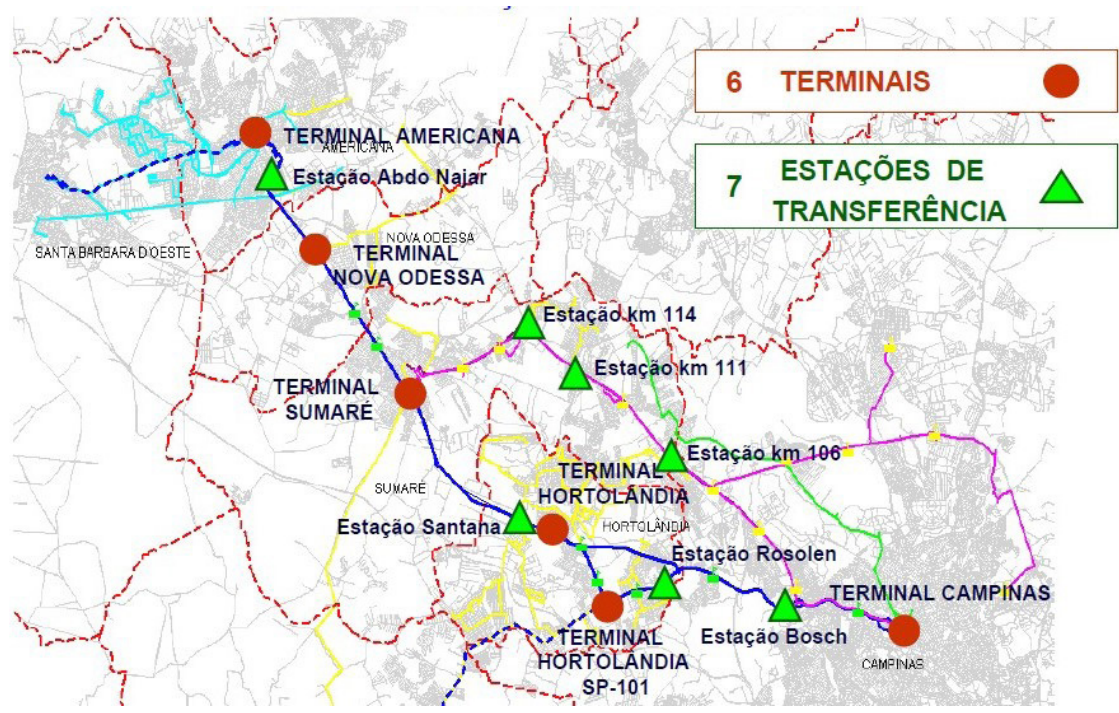

Fonte: EMTU, 2005.

Os novos terminais estão localizados longe dos centros de atração de viagens nos municípios e em pontos onde não é possível a articulação tronco-alimentadora dos ônibus, portanto, infere-se que as justificativas técnicas não explicam o seu deslocamento geográfico. A figura 3, porém, ilustra a ideia de que a promoção imobiliária pode ter guiado as autoridades municipais a exigirem da EMTU essas respectivas topologias A pedido das prefeituras ${ }^{6}$, os dois novos terminais foram implantados em áreas de expansão urbana, dotando-as de excepcional acessibilidade aos transportes coletivos, renovando o sistema viário adjacente e proporcionando intervenções paisagísticas relevantes. Assim como seus valores de uso, elevaram-se também seus valores de troca. 


\section{Figura 3}

LOCALIZAÇÃO DOS TERMINAIS METROPOLITANOS DE ÔNIBUS DE HORTOLÂNDIA (ACIMA) E DE SANTA BÁRBARA D’OESTE (ABAIXO) EM MEIO ÀS ÁREAS DE EXPANSÃO URBANA (2015)
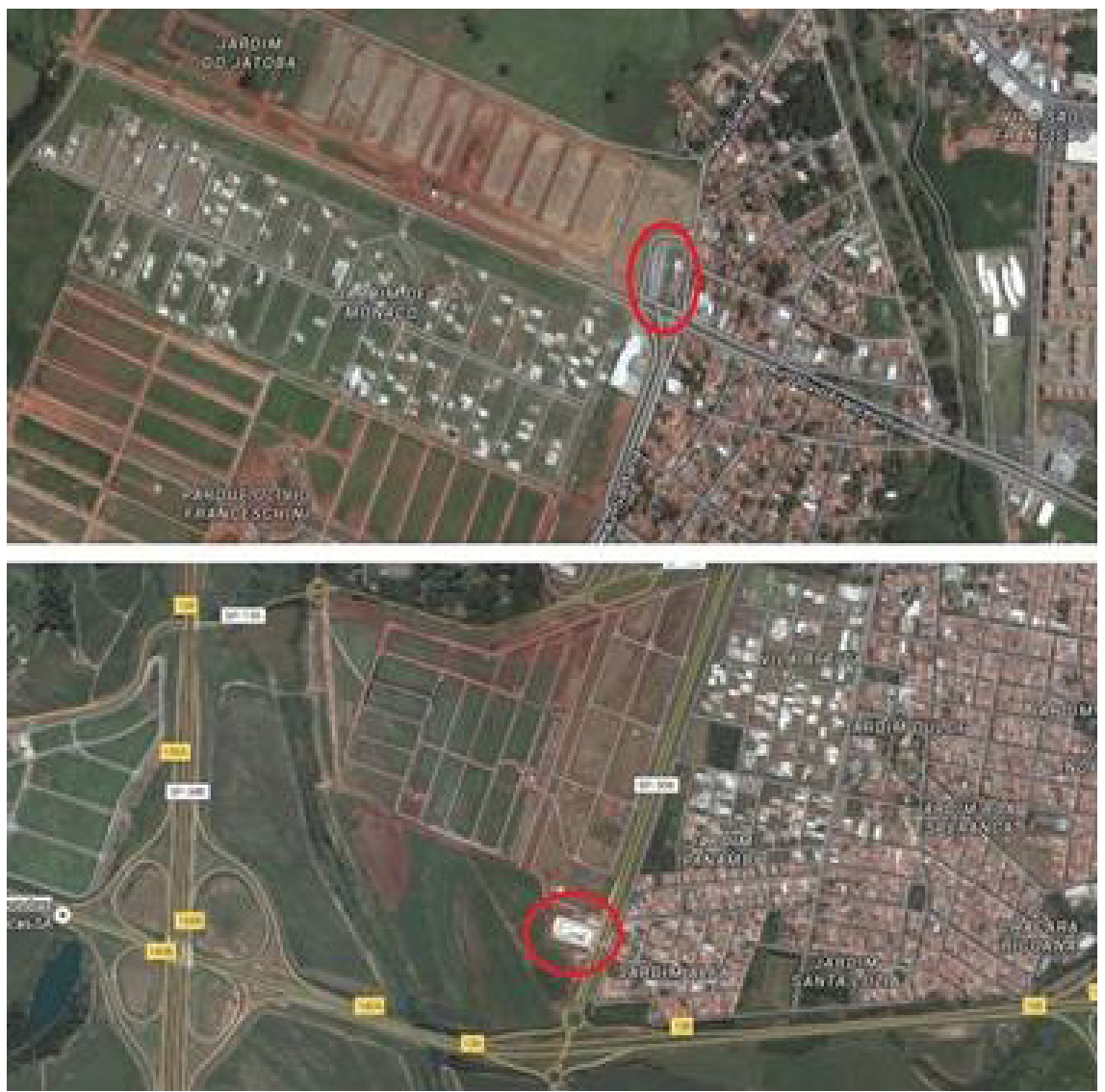

Montagem do autor. Fonte das imagens: Google Maps. Disponível em: www.google.com. Acesso em: 23/06/2015.

Financiados pela totalidade dos cidadãos, esses novos terminais e as demais mudanças no projeto vêm contribuindo com a apropriação da renda da terra por um número reduzido de promotores imobiliários. Enquanto isso, a maior parte dos usuários de transporte coletivo continua sendo tributada para pagar um projeto cuja infraestrutura não vem trazendo retorno proporcional, em termos de qualidade de serviço público. Uma parte dos milhões investidos no corredor se transformou em renda da terra antes de se tornar um ativo na ampliação da mobilidade urbana, e exemplifica a lógica da acumulação capitalista por espoliação. 


\section{Privatização do patrimônio público}

No ano de 2014, toda a infraestrutura implantada e em implantação para operação de transporte metropolitano na RMC foi adjudicada ao Consórcio Bus + por um prazo de quinze anos ${ }^{7}$. Formado pelas empresas Capellini (líder), Salamanca, Campestre, Expresso Metrópoles, Expresso Fênix e Jota Jota, o Consórcio Bus + tornou-se responsável pela operação, pela manutenção e pela conservação de todos os terminais, estações, abrigos, pontos de parada e sistema viário necessários à circulação dos ônibus metropolitanos dos vinte municípios da região. Assumiu essa responsabilidade como contrapartida pela exploração dos serviços regulares de ônibus intermunicipais da RMC, cuja receita estimada no quindênio é de R 2,5 bilhões.

A concessão onerosa de serviços públicos à iniciativa privada é um dos meios de desestatização previstos nas legislações federal e estadual. Tem caráter menos assertivo que a alienação de bens públicos, uma vez que o objeto pode retornar ao Estado após o período contratual. Na formação socioespacial brasileira, porém, guarda um elemento essencial da dinâmica geral de privatização, o que permite incorporá-la ao conjunto de mecanismos de acumulação por espoliação. No caso específico em discussão, a relação se dá entre uma escala não local do poder estatal - o governo estadual - e a dimensão de poder corporativo formada pelas empresas operadoras de ônibus.

Araújo (2010) sintetiza as discussões críticas acerca da desestatização de empresas públicas brasileiras a partir da década 1990. A maioria só pôde ser vendida porque havia garantias de valorização e lucratividade, sendo suficientemente estruturadas durante o período estatal para permanecerem competitivas no mercado após sua transferência ao capital privado. Os serviços de transporte público, por outro lado, enfrentam uma constante fragilidade econômico-financeira que limita sua plena privatização. Autores como Belda (1994) e Vasconcellos (1996) destacam os aspectos principais dessa crise. Primeiramente, os custos para a operação dos sistemas são crescentes, na medida que são proporcionais ao crescimento espraiado das áreas urbanizadas - o que se reverte em mais quilômetros rodados diariamente pelos veículos. Enquanto isso, as receitas são rígidas e decrescentes, respectivamente, por causa dos conflitos políticos em torno das tarifas e pelo êxodo contínuo em direção às modalidades individuais de transporte motorizado.

50. GeoTextos, vol. 16, n. 2, dezembro 2020. V. da Silva. 37-58 


\section{Figura 4}

REPRESENTAÇÃO DAS PERMISSÕES PÚBLICAS DAS LINHAS METROPOLITANAS DE ÔNIBUS

DA RMC, POR EMPRESA, ANTES DA CONCESSÃO (2012)

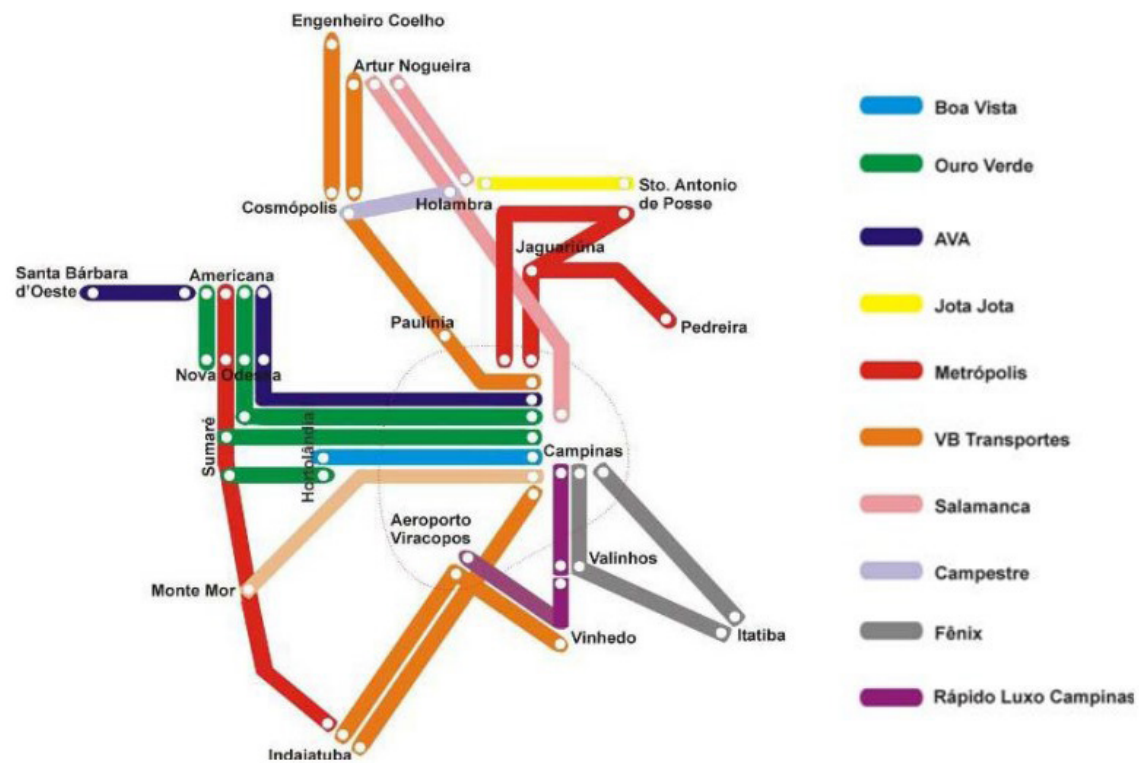

Fonte: EMTU. Disponível em: www.emtu.sp.gov.br. Acesso em: 27/04/2016.

Com raras exceções, a operação dos transportes coletivos tende a ser onerosa aos operadores. Daí que o equilíbrio econômico-financeiro do sistema precisa ser obtido pelo aumento da tarifa, por meio de subsídios estatais ou pela precarização do serviço. Na RMC, até 2014, a precarização como solução à crise nos transportes públicos perdurara no sistema metropolitano de ônibus. Através das permissões públicas, empresários locais operavam ligações intermunicipais específicas, estabelecendo oligopólios com forte componente territorial (figura 4). Sob essa modalidade, usufruíam da relativa liberdade para flexibilizar o serviço e torná-lo financeiramente viável - isto é, superlotando itinerários e horários com alta demanda e suprimindo ou marginalizando itinerários e horários com déficit tarifário (COCCO, 2011). Desnecessário dizer que a redução de custos nesse esquema é diretamente proporcional à queda da qualidade do sistema.

Em sua justificativa, a concessão onerosa dos ônibus metropolitanos da RMC foi apresentada como um instrumento de regulação mais incisivo 
do poder público estadual sobre a qualidade do serviço prestado. Além disso, também apareceu como um meio menos custoso ao Estado de realizar certos investimentos, destacando-se a implantação da bilhetagem eletrônica integrada, a renovação periódica da frota e a manutenção da infraestrutura implantada e a ser implantada ${ }^{8}$. Essa proposta só é viável, contudo, se o Estado subsidia o sistema ao ponto de se reestabelecer seu equilíbrio econômico-financeiro sem que a operação recorra ao corte de gastos pela precarização. É aí que entra o projeto do Corredor Metropolitano Noroeste.

Em seu papel na viabilização da concessão pública, o Corredor Metropolitano Noroeste pode ser visto como um fixo balizador de novos fluxos, provendo racionalidade a certa porção do espaço geográfico (SANTOS; SILVEIRA, 2001). Se tomada a perspectiva tecnocrática, tratar-se-ia de um projeto que prevê a melhoria dos serviços ao mesmo tempo que desonera o Estado. Mas os pressupostos teóricos deste artigo recusam a visão de neutralidade. É na compreensão do projeto como instrumento de exercício de poder no território que transparecem os sutis contornos da acumulação por espoliação que o envolvem.

O ponto de partida nesse esforço é reconhecer o papel da EMTU na consolidação de oligopólios territoriais no setor do transporte público. Apesar dos supostos benefícios da concorrência em um livre mercado estarem no centro da ideologia de privatização, a prática de alienações e concessões públicas parece levar ao fortalecimento dos mesmos grupos empresariais de sempre. Na contramão da suposta competitividade de mercado, o governo estadual interveio normativamente e eliminou a disputa por usuários, de início suprimindo a operação das vans e peruas que concorriam com os serviços regulares de ônibus. Depois de firmada a primazia dos ônibus sobre os perueiros, o Consórcio Bus + pôde assegurar um oligopólio estável na RMC, com garantias por parte do poder concedente aos mesmos operadores que outrora eram permissionários. Outrossim, a empresa líder do consórcio - Transportes Capellini Ltda. - é integrante do Grupo Belarmino, do qual também fazem partes as antigas permissionárias Boa Vista, Ouro Verde, AVA, Rápido Luxo Campinas e VB Transportes, representadas na figura 4. Até o início do contrato de 
concessão, as empresas desse grupo transportavam 96,2\% dos usuários de transporte coletivo intermunicipal da RMC (SALOMÃO, 2014).

Transferir as infraestruturas de transporte metropolitano implantadas pelo Estado junto à concessão garante ao Consórcio Bus + uma espécie de renda excedente. Isso porque o investimento é financiado pela totalidade dos cidadãos, à medida que os recursos provêm diretamente do Tesouro do Estado de São Paulo. Além do aumento da qualidade, tais investimentos reduzem custos operacionais dos ônibus e atraem mais usuários, implicando em um aumento da receita tarifária. Mas a concessão impossibilita que esse retorno seja encaminhado ao Estado para reaver o dinheiro investido e possibilitar novas ações públicas; em vez disso, é apropriado pelas concessionárias, a despeito de não terem participado em qualquer intervenção infraestrutural do Corredor Metropolitano Noroeste.

No contexto do projeto analisado, a privatização do patrimônio público por meio de concessões onerosas é concebida como mecanismo de acumulação por espoliação porque também se vale do Estado como instrumento de socialização dos custos e riscos de um investimento, mas os benefícios são quase que totalmente apropriados por um grupo pequeno de pessoas. Nesse caso, o oligopólio de empresas do consórcio conta com a conivência e a colaboração do poder público estadual, via EMTU, para assumir as inseguranças e o endividamento inerentes aos milionários investimentos infraestruturais necessários ao corredor de ônibus. São investimentos volumosos e com riscos agravados pelos conflitos de interesses que envolvem outros tantos agentes estatais, empresariais e da sociedade civil. O Consórcio Bus + não colabora com esses investimentos, mas colhe todos os benefícios inerentes a um sistema de ônibus mais estruturado, com maior rentabilidade e equilíbrio econômico-financeiro.

Pinheiro e Fukusaku (2000) afirmam que o principal impulso de desestatização no Brasil advém das políticas para contenção da dívida pública, com vistas ao equilíbrio das contas estatais. Mas o modelo de financiamento público de grandes obras urbanas e posterior concessão da operação vai no sentido contrário, pois priva o Estado de arrecadar recursos que compensariam suas inversões. O resultado é o aumento do endividamento dos governos, o que reforça a adoção de políticas de austeridade fiscal, contenção de gastos em setores e lugares prioritários, necessidade de 
empréstimos a juros cada vez mais altos e, assim, mais endividamento. Por isso, Chesnais (2010) condena a privatização do patrimônio público como um mecanismo perverso imposto pelo receituário neoliberal, que agrava a instabilidade sistêmica da economia contemporânea. Trata-se de um formidável meio de espoliar a sociedade em favor da acumulação capitalista.

\section{Considerações finais}

Décadas de políticas rodoviaristas priorizaram a circulação de automóveis em detrimento das demais modalidades e tornaram o trânsito das cidades brasileiras congestionado e violento (VASCONCELLOS, 1996). Por conta disso, os projetos de ampliação das infraestruturas voltadas ao transporte público costumam ser muito bem quistos por todo o senso comum, por tecnocratas, pela classe política e até mesmo pelos acadêmicos críticos. A ação do poder corporativo - planejadores, construtores, promotores imobiliários, instituições de financiamento e operadoras de transporte público - é equivocadamente tratada como marginal, subsequente e, muitas vezes, colaborativa. O que se propõe aqui, porém, é que seus interesses devem ser considerados como verdadeiros promotores dos empreendimentos, condicionando sua viabilidade de implantação efetiva. Os grupos especuladores têm papel ativo no rizoma de actantes que dá sustentação aos projetos, como o corredor em questão, e seus interesses especulativos são determinantes.

No caso do Corredor Metropolitano Noroeste, os conflitos acerca das diretrizes de traçado e disposição dos equipamentos funcionais à circulação de ônibus se dão explicitamente entre o governo estadual e os governos municipais, mas, na verdade, representam também os embates entre os blocos de poder que orbitam em torno de si. A EMTU, ao defender o projeto o mais próximo do original possível, não o faz apenas em prol dos usuários que serão beneficiados. Na verdade, se coloca como defensora de uma proposta rentável à concessão pública dos serviços de ônibus metropolitanos, regulado pelo governo paulista e operada pelo oligopólio regional de empresas do setor. Os governos municipais, por outro lado, servem como articuladores dos interesses dos promotores imobiliários 
locais, que metamorfizam o projeto em busca da apropriação privada da renda da terra gerada coletivamente.

O método geográfico aqui defendido tem a função de elucidar essa penetração da lógica de acumulação em todos os processos de renovação das materialidades. Converte, inclusive, sistemas de objetos e discursos outrora voltados ao bem-estar social em mecanismos de reprodução do sistema capitalista.

\section{Notas}

1 A ideia de um rizoma de actantes está associada à teoria do ator-rede de Latour (2008; 2013), que possibilita a análise integrada de um conjunto de agentes humanos (pessoas físicas e jurídicas) e não humanos (os sistemas de objetos geográficos) em torno de um projeto. É sua ação como totalidade integrada e coletiva que dá sustentação ou não a um projeto de organização do território, a uma "âncora no futuro", como o corredor analisado neste texto.

2 O nome oficial "Corredor Metropolitano Vereador Biléo Soares" foi atribuído pela Lei Estadual $N^{\circ}$ 15.174, de 2013. A denominação original, no entanto, ainda é amplamente utilizada pelos agentes envolvidos e foi preférida na redação deste artigo.

3 Valores de 2006, referentes às concorrências 001/2006, 002/2006 e 003/2006 da EMTU. Disponível em: www.imprensaoficial.com.br. Acesso em: 27/04/2016.

4 Valores de 2014, referentes às concorrências 009/2013 e 004/2014 da EMTU. Disponível em: www.imprensaoficial.com.br . Acesso em: 27/04/2016.

5 Conforme entrevistas realizadas pelo autor junto à Gerência Regional de Campinas (GRC, em 02/09/2013), à Gerência de Logística Integrada (GLI, em 10/ 12/2013) e ao Departamento de Elaboração de Projetos (DEP, em 13/09/2016) da EMTU.

6 Idem.

7 Referente à concorrência 003/2012 da EMTU. Disponível em: www.imprensaoficial.com.br. Acesso em: 27/04/2016.

8 Idem

\section{Referências}

ANTAS JR., R. M. Elementos para uma discussão epistemológica sobre a regulação no território. Geousp - Espaço e Tempo, n. 16, p. 81-86, 2004.

ARAÚJO, J. P. Privatizações: Entre 1994/2002 125 estatais vendidas por US\$ 105,553 bilhões. Não às privatizações! FPA de Fato (Blog), 2010. Disponível em: www.fpabramo.org.br. Acesso em 17/05/2016.

BELDA, R. Caminhos do transporte urbano. São Paulo: Editoras Unidas, 1994. 
BRANDÃO, C. R. F. Acumulação primitiva permanente e desenvolvimento capitalista no Brasil contemporâneo. In: ALMEIDA, A. W. B. et al. Capitalismo globalizado e recursos territoriais. Rio de janeiro: Lamparina, 2010. p. 39-69.

BRASIL. Constituição da República Federativa do Brasil, promulgada em 5 de outubro de 1988. 1988. Disponível em: www.planalto.gov.br. Acesso em: $18 / 09 / 2016$.

CASTILLO, R.; TOLEDO JR., R.; ANDRADE, J. Três dimensões de solidariedade em Geografia: autonomia político-territorial e tributação. Revista Experimental - LABOPLAN, São Paulo, ano II, n. 3, p. 69-99,1997.

CATAIA, M. A. Território usado e federação: articulações possíveis. Educação \& Sociedade, v. 34, n. 125, 2013.

CHESNAIS, F. A finança mundializada. São Paulo: Boitempo, 2010.

COCCO, R. G. Interações espaciais e sistemas de transporte público: uma abordagem para Bauru, Marília e Presidente Prudente. 2011. 265 f. Dissertação (Mestrado em Geografia) - Faculdade de Ciências e Tecnologia, UNESP, Presidente Prudente, 2011.

DIAS, L. C. Os sentidos da rede: notas para discussão. IN: DIAS, L. C.; SILVEIRA, R. L. L. (Org.). Redes, sociedades e territórios. Santa Cruz do Sul: Edunisc, 2005. p. 11-28.

EMPRESA METROPOLITANA DE TRANSPORTES URBANOS (EMTU). Corredor Metropolitano Noroeste. (Apresentação de Slides), 2005. Disponível em: www.stm.sp.gov.br.

FERNANDES, A. C. A.; BRANDÃO, C. A.; CANO, W. A Região Metropolitana de Campinas - análise integrada. In: CANO, W.; BRANDÃO, C. A. (Coord.). A Região Metropolitana de Campinas: urbanização, economia, finanças e meio ambiente - volume 2. Campinas: Editora da Unicamp, 2002. p. 55-94.

FIX, M. São Paulo, cidade global: fundamentos financeiros de uma miragem. São Paulo: Boitempo, 2007.

FOUCAULT, M. Em defesa da sociedade. São Paulo: Martins Fontes, 2005.

FUNDAÇÃO ECONOMIA DE CAMPINAS (FECAMP). Plano Integrado de Transportes Urbanos da Região Metropolitana de Campinas (PITU Campinas): relatório 8 - elaboração das estratégias para cada cenário - revisão A, 2006. Disponível em: www.fecamp.org.br. 
FUNDAÇÃO PARA PESQUISA E ARQUITETURA EM AMBIENTE (FUPAM). Estudo de Impacto Ambiental (EIA): variante do lote 2 do Corredor Noroeste de Campinas. São Paulo: FUPAM, 2016.

GALLO, F. Elementos da formação territorial brasileira: a federação nacional como evento geográfico. Boletim Campineiro de Geografia, v. 4, n. 1, p. 27-43, 2014.

HARVEY, D. O novo imperialismo. São Paulo: Loyola, 2004.

O enigma do capital. São Paulo: Boitempo, 2011.

KOWARICK, L. A espoliação urbana. Rio de Janeiro: Paz e Terra, 1979.

LATOUR, B. Reensamblar lo social: una introducción a la teoría del actor-red. Buenos Aires: Ediciones Manantial, 2008.

On recalling ANT. Department of Sociology, Lancaster University, Lancaster, 2013.

MARX, K. O capital: crítica da economia política. Livro Primeiro - o processo de produção do capital: Tomo 2. São Paulo: Nova Cultura, 1996 [1867].

PINHEIRO, A. C.; FUKUSAKU, K. A privatização no Brasil: o caso dos serviços de utilidade pública. Rio de Janeiro: BNDES; FINAME, 2000.

RAFFESTIN, C. Por uma geografia do poder. São Paulo: Ática, 1993.

RODRIGUES, A. M. Moradia nas cidades brasileiras. São Paulo: Contexto, 1996.

SALOMÃO, V. O transporte de passageiros na Região Metropolitana de Campinas: organização, regulação e usos do território. Monografia (Bacharelado em Geografia) - Instituto de Geociências, UNICAMP, Campinas, 2014.

A ampliação das redes de transporte público no estado de São

Paulo: articulações institucionais e usos do território. 2017. 360f. Dissertação (Mestrado em Geografia) - Instituto de Geociências e Ciências Exatas, UNESP, Rio Claro, 2017.

SÃO PAULO (ESTADO). Secretaria dos Transportes Metropolitanos. Pesquisa Origem e Destino RMC. (Apresentação de Slides). 2003. Disponível em: www. stm.sp.gov.br. Acesso em: 16/12/2015.

SANTOS, M. O espaço geográfico como categoria filosófica. Revista Terra Livre, n. 5, p. 9-20, 1988.

A natureza do espaço. São Paulo: Hucitec, 1996. 
SANTOS, M.; SILVEIRA, M. L. O Brasil: território e sociedade no início do século XXI. Rio de Janeiro: Record, 2001.

SECRETARIA DE TRANSPORTES METROPOLITANOS (STM). Pesquisa de Origem e Destino Domiciliar e Pesquisa de Linha de Contorno na Região Metropolitana de Campinas. São Paulo: Oficina Engenheiros Consultores Associados, 2012.

VASCONCELLOS, E. A. Transporte urbano nos países em desenvolvimento: reflexões e propostas. São Paulo: Editoras Unidas, 1996.

VILLAÇA, F. Espaço intra-urbano no Brasil. São Paulo: Studio Nobel, 2001.

Recebido em: 16/07/2020

Aceito em: 20/07/2020 